\title{
Analisis Hubungan Pengetahuan tentang Deteksi Dini Kanker Payudara pada Remaja Putri melalui Pemeriksaan Payudara Klinis (SADANIS)
}

\author{
Sri Restu Tempali \\ Prodi D-III Kebidanan Palu, Jurusan Kebidanan, Poltekkes Kemenkes Palu \\ Email korespondensi: restutempali@gmail.com
}

Article Info

ABSTRACT

Article history:

Submitted: 2019-02-21

Accepted: 2019-04-16

Published: 2019-04-22

Keywords:

Knowledge; Early Detection of Breast Cancer; Adolescent;
Fibroadenoma is the most benign breast neoplasm. These tumors grow in young women with the highest frequency in young women 21-25 years, with a prevalence of more than $9 \%$ of the female population affected by fibroadenoma. Breast cancer still has a high likelihood of being cured when it comes early or early. Early detection of breast cancer is an examination program to recognize breast cancer while still small, and before the cancer has a chance to spread. One of the early detection efforts is clinical breast examination (SADANIS) which is carried out at least once every 3 years or if abnormalities are found in the process of selfbreast examination (BSE) and carried out by trained health workers. The purpose of the study was to determine the relationship between knowledge and early detection of breast cancer risk in young women through SADANIS examination. Observational research method with cross sectional approach. The sample is a student of SMK 1 Palu and a student of AKBID Cendrawasih Palu. The results showed that there was a significant relationship between knowledge about SADANIS examination and the practice of SADANIS examination in young women so there is a strong relationship between young women's knowledge BSE in early detection of breast cancer as evidenced by the $p$-value $0.007<\alpha(0.05)$. The conclusion is that the knowledge of young women about sadanis examination is still low.

\section{PENDAHULUAN}

Fibroadenoma mammae biasanya terjadi pada wanita usia muda, yaitu pada usia remaja atau sekitar 20 tahun. fibroadenoma umumnya terjadi pada wanita dengan usia 21-25 tahun, kurang dari 5\% terjadi pada usia di atas 50 tahun, sedangkan prevalensinya lebih dari $9 \%$ populasi wanita terkena fibroadenoma. ${ }^{1}$ Tumor payudara telah banyak di temukan pada usia muda, bahkan remaja putri usia 14 tahun yang menderita tumor di payudaranya di mana tumor dapat berpotensi menjadi kanker bila tidak terdeteksi lebih awal, meskipun tidak semuanya ganas tetapi ini menunjukkan bahwa saat ini sudah ada tren gejala kanker payudara yang semakin tinggi di usia remaja. ${ }^{2}$ Kanker payudara masih mempunyai kemungkinan besar untuk disembuhkan ketika datang masih tahap awal atau dini. Upaya deteksi dini kanker payudara adalah program pemeriksaan untuk mengenali kanker payudara sewaktu masih berukuran kecil, dan sebelum kanker tersebut mempunyai kesempatan untuk menyebar. ${ }^{2}$ Prevensi dan deteksi dini pencegahan (primer) adalah usaha agar tidak terkena kanker payudara dengan mengurangi atau meniadakan faktor-faktor risiko yang diduga sangat erat kaitannya dengan peningkatan insiden kanker payudara. upaya deteksi dini yaitu Pemeriksaan klinis payudara (SADANIS) 
yang dilakukan sekurangnya 3 tahun sekali atau apabila ditemukan adanya abnormalitas pada proses pemeriksaan payudara sendiri (SADARI) dan dilakukan oleh petugas kesehatan terlatih. ${ }^{3}$

Menurut data WHO Tahun 2018 Kanker paru-paru dan payudara wanita adalah jenis utama di seluruh dunia dalam hal jumlah yang kasus baru; untuk masing-masing jenis ini, sekitar 2,1 juta diagnosis diperkirakan pada tahun 2018, berkontribusi sekitar $11,6 \%$ dari total beban kejadian kanker. Kanker kolorektal (1,8 juta kasus, $10,2 \%$ dari total) dan Payudara perempuan kanker peringkat sebagai penyebab utama kematian kelima (627.000 kematian, 6,6\%), setidaknya di negaranegara yang lebih maju. terlebih untuk negara miskin dan berkembang kejadiannya akan lebih cepat. ${ }^{4}$ Kanker tertinggi di Indonesia pada perempuan adalah kanker payudara dan kanker leher Rahim. Sedangkan pada laki-laki adalah kanker paru dan kanker kolorektal. Merujuk data yang dipaparkan Kemenkes per 31 Januari 2019, terdapat angka kanker payudara 42,1 per 100.000 penduduk dengan rata-rata kematian 17 per 100.000 penduduk dan kanker serviks sebesar 23,4 per 100.000 penduduk dengan rata-rata kematian 13,9 per 100.000 penduduk di Indonesia. ${ }^{5}$

Berdasarkan data dari dinas kesehatan provinsi Sulawesi tengah pada tahun 2014 terdapat 57 jumlah kasus kanker payudara, selanjutnya terjadi peningkatan pada tahun 2015 menjadi 76 kasus kanker payudara. ${ }^{6,7}$ Berdasarkan data dari dinas kesehatan kota palu pada tahun 2015 terdapat 23 kasus kanker payudara dan pada tahun 2016 terdapat 39 jumlah kasus kanker payudara. berdasarkan data tersebut dapat di lihat bahwa kejadian kanker payudara terus meningkat dari tahun ke tahun. ${ }^{8,9}$ AKBID Cendrawasih Palu khususnya mahasiswa tingkat I perlu mendapat gambaran tentang deteksi resiko kanker payudara melalui pemeriksaan SADANIS dan memberikan pengetahuan dan wawasan baik terhadap dirinya sendiri sehingga dapat dikembangkan pada masyarakat umumnya tentang resiko kanker payudara, begitu pula SMKN 1 kelas XI Palu dapat menjadikan acuan dalam mendeteksi resiko dini kanker payudara terhadap dirinya sendiri melalui pemeriksaan SADANIS dan pesertanya homogen untuk kelas XI.Tujuan penelitian ini adalah mengetahui hubungan pengetahuan dengan deteksi dini risiko kanker payudara pada remaja putri melalui pemeriksaan SADANIS.

\section{METODE PENELITIAN}

Penelitian ini menggunakan jenis penelitian kuantitatif (observasional) dengan pendekatan cross sectional. Penelitian telah dilaksanakan di SMKN 1 Palu dan AKBID Cendrawasih Palu tahun 2018 pada 7 Agustus - 4 Nopember 2018. Populasi dalam penelitian ini adalah semua remaja putri kelas $\mathrm{XI}$ jurusan tata busana dan tata boga di SMKN 1 Palu berjumlah 38 orang dan Mahasiswa AKBID Cendrawasih Palu tingkat 1 berjumlah 35 orang sehingga jumlah populasi berjumlah 73 orang. Sampel adalah siswi SMKN 1 Palu kelas XI Jurusan karena SMKN 1 Palu dan AKBID Cendrawasih Palu Tingkat 1 semuanya wanita dan rata-rata berusia 16-18 tahun. Jumlah sampel sebanyak 73 orang yang dipilih secara total population. Variabel independent dalam penelitian ini yaitu pengetahuan dan pemeriksaan payudara dan variabel dependent adalah SADANIS. Alat ukur dan pengumpulan data yang digunakan dalam penelitian ini adalah data primer dan data sekunder. Data primer meliputi: data yang diperoleh dari responden melalui pengisian kuesioner dengan aspek pengetahuan dan pemeriksaan deteksi dini kanker payudara pada seluruh responden. Data sekunder adalah data yang diperoleh dari SMKN 1 PALU meliputi nama dan jumlah siswa berdasarkan surat keputusan dari sekolah. Pengolahan data dengan menggunakan sistem komputerisasi kemudian akan dianalisis secara 
univariat menggunakan distribusi frekuensi dan bivariat menggunakan Chi-square. Penelitian ini menggunakan beberapa strategi untuk menjaga standar kualitas data. Kontrol pertama diawali dengan menyeleksi tenaga bidan yang terlatih dalam melakukan SADANIS dan memiliki kemampuan untuk mengumpulkan data melalui analisis hasil pemeriksaan. Sebelum ke lapangan, peneliti dan pemeriksa menyamakan persepsi tentang pemeriksaan SADANIS.

\section{HASIL PENELITIAN}

Hasil penelitian dapat disajikan sebagai berikut:

\section{Karakteristik Responden}

Tabel 1. Gambaran Karakterisitik Responden Remaja Putri di Akademi Kebidanan Cendrawasih Palu dan SMKN 1 Palu.

\begin{tabular}{lrr}
\hline Variabel & Frekuensi & $\mathbf{\%}$ \\
\hline Umur (tahun) & 3 & \\
16 & 34 & 4,1 \\
17 & 30 & 41,1 \\
18 & 4 & 5,5 \\
19 & 2 & 2,7 \\
20 & & \\
Umur Menarche (tahun) & 60 & 82,2 \\
$\quad 12-14$ & 13 & 17,8 \\
$15-17$ & & \\
Siklus Haid & 43 & 58,9 \\
$\quad$ Teratur & 30 & 41,1 \\
Tidak Teratur & & \\
Riwayat Keluarga Tumor / Kanker & 9 & 12,3 \\
$\quad$ Ada & 64 & 87,7 \\
Tidak Ada & & \\
Hasil Pemeriksaan SADANIS & 3 & 4,11 \\
$\quad$ Positif & 70 & 95,89 \\
$\quad$ Negatif & & \\
\hline
\end{tabular}

Sumber: Data primer, 2018

Pada tabel 1 terlihat bahwa umur responden sebagian besar berada pada usia remaja khususnya remaja akhir dengan menarce sebagian besar pada usia 12-24 tahun. Siklus haid yang tidak teratur cukup tinggi yaitu mencapai $41,1 \%$. Terdapat sebagian kecil $(12,3 \%)$ responden yang memiliki riwayat keluarga tumor/kanker.

\section{Gambaran Variabel Utama Penelitian}

Tabel 2 Gambaran Variabel Utama Penelitian pada Remaja Putri di Akademi Kebidanan Cendrawasih Palu dan SMKN 1 Palu.

\begin{tabular}{lccc}
\hline \multicolumn{1}{c}{ Variabel $(\mathbf{n = 7 3 )}$} & $\mathbf{n}$ & $\mathbf{\%}$ & Rerata (min-max \\
\hline Pengetahuan & & & $6,7(3-10)$ \\
$\quad$ Kurang & 34 & 46,6 & $60,5(27,3-90,9)$ \\
Cukup & 27 & 37,0 & \\
$\quad$ Baik & 12 & 16,4 & \\
Pemeriksaan SADANIS & & & \\
Ya & 9 & 12,3 & \\
$\quad$ Tidak & 64 & 87,7 & \\
\hline
\end{tabular}

Sumber : Data primer, 2018. 
Untuk variabel pengetahuan pada tabel 2 dapat dilihat bahwa sebagian besar responden memiliki pengetahuan yang kurang yaitu sebesar $46,6 \%$ dan hanya sebagian kecil responden yang memiliki pengetahuan yang baik yaitu sebesar $16,4 \%$. Jika dilihat dari skor pengetahuan, diketahui bahwa skor rata-rata adalah $6,66(60,51 \%)$ dengan skor terendah yaitu $3(27,3 \%)$ dan skor tertinggi yaitu 10 $(90,9)$ dari 11 pertanyaan pengetahuan. Untuk pemeriksaan SADANIS cukup rendah yaitu hanya 9 orang $(12,3 \%)$ yang melakukan pemeriksaan SADANIS

\section{Hubungan antar Variabel}

Tabel 3. Hubungan Pengetahuan dengan Praktik Pemeriksaan SADANIS pada Remaja Putri di Akademi Kebidanan Cendrawasih Palu dan SMKN 1 Palu

\begin{tabular}{lccccc}
\hline \multirow{3}{*}{ Pengetahuan } & \multicolumn{4}{c}{ Pemeriksaan SADANIS } & \multirow{2}{*}{ Nilai p } \\
\cline { 2 - 5 } & \multicolumn{4}{c}{ Ya } & \multicolumn{2}{c}{ Tidak } & \\
\cline { 2 - 5 } & $\mathrm{n}$ & $\%$ & $\mathrm{n}$ & $\%$ & \\
\hline Cukup & 5 & 8,2 & 56 & 91,8 & \\
Baik & 4 & 33,3 & 8 & 66,7 & \multirow{2}{*}{0,005} \\
\hline Total & 9 & 12,3 & 64 & 87,7 & \\
\hline
\end{tabular}

Sumber : Data primer, 2018

Hubungan antara variabel bebas dengan variabel terikat pada tabel 3 memperlihatkan bahwa responden yang memiliki pengetahuan cukup hanya $8,2 \%$ yang melakukan pemeriksaan SADANIS, dan pada responden yang memiliki pengetahuan baik sepertiga diantaranya melakukan pemeriksaan SADANIS. Hal ini menunjukkan bahwa semakin baik pengetahuan remaja putri maka semakin tinggi kemungkinannya untuk melakukan pemeriksaan SADANIS. Hasil uji statistik dengan chi-square menunjukkan bahwa ada hubungan yang bermakna antara pengetahuan dengan pemeriksaan SADANIS $(P=0,005 ; P<\alpha(0,05))$.

\section{PEMBAHASAN}

Hasil penelitian ini menunjukkan bahwa ada hubungan yang bermakna antara pengetahuan tentang pemeriksaan SADANIS dengan praktik pemeriksaan SADANIS pada remaja putri. Sejalan dengan penelitian Wantini dan Indrayani (2018) bahwa ada hubungan kebermaknaan antara pengetahuan dengan deteksi dini kanker payudra melalui pemeriksaan SADANIS berdasarkan uji Fisher Exact's dengan nilai $p$-value $0,012<\alpha(0.05),{ }^{10}$ demikian pula ada hubungan yang kuat antara pengetahuan remaja putri tentang SADARI dalam deteksi dini kanker payudara yang dibuktikan dengan nilai $p$-value $0,007<\alpha(0.05){ }^{2}$

Adanya hubungan pada kedua variabel ini menunjukkan hal yang baik dalam upaya pencegahan dan penanggulangan masalah kanker/tumor khususnya kanker payudara, hal akan mendukung terbentuknya pola perilaku yang baik sebagaimana dalam Notoatmodjo (2012) bahwa salah satu faktor predisposisi (predisposing factors) dalam teori perilaku dapat terwujud melalui pengetahuan, sikap, kepercayaan, keyakinan, dan nilai-nilai. Berdasarkan data yang ada, menunjukkan bahwa semakin tinggi tingkat pengetahuan responden remaja dalam penelitian ini maka semakin baik pula praktik pemeriksaan SADANIS yang dilakukan. ${ }^{11}$

Fakta yang ditemukan dalam penelitian ini menunjukkan bahwa tingkat pengetahuan responden tentang pemeriksaan SADANIS masih sangat rendah yaitu hanya $16,4 \%$ yang memiliki pengetahuan dengan kategori baik. Selain itu skor ratarata jawaban responden hanya $60,51 \%$ yang tergolong masih rendah, bahkan nilai 
terendah dari jawaban responden yaitu kurang dari 30\% dari total skor. Hal ini tentu saja memberi penjelasan kepada kita bahwa masih sangat diperlukan eduakasi

Praktik pemeriksaan SADANIS tidak terlalu berbeda hasilnya dengan tingkat pengetahuan, yaitu hanya 9 orang dari 73 responden yang melakukan praktik pemeriksaan SADANIS. Tentu hal ini sangat sejalan karena jika tingkat pengetahuan rendah maka tingkat praktik pun akan rendah pula. Dengan memperhatikan data yang ada, maka praktik pemeriksaan SADANIS seharusnya persentase pelaksanaannya tinggi karena $41,1 \%$ responden memiliki siklus haid yang tidak teratur sehingga risikonya semakin besar dan oleh karena itu pemeriksaan SADANIS seharusnya dapat dilakukan mendeteksi secara dini adanya kelainan.

Dalam penelitian ini dilaksanakan pula pemeriksaan SADANIS oleh peneliti dan hasilnya ditemukan sebanyak 3 orang positif ada benjolan pada payudara, sedangkan 5 orang lainnya suspect. Oleh karena itu, pemeriksaan SADANIS saat ini tentu saja sangat diperlukan baik dilakukan oleh tenaga kesehatan maupun dilakukan sendiri oleh remaja putri di Kota Palu, dan hal ini akan meningkat pelaksanaannya jika ditunjang pula oleh peningkatan pengetahuan.

\section{SIMPULAN DAN SARAN}

Penelitian ini menyimpulkan bahwa pengetahuan remaja putri tentang pemeriksaan sadanis masih rendah. Ada hubungan yang bermakna antara pengetahuan dengan deteksi dini kanker payudara melalui pemeriksaan sadanis. Penelitian ini menyarankan kepada pihak sekolah dan perguruan tinggi agar menjalin kolaborasi yang berkelanjutan dengan pihak Puskesmas setempat untuk secara periodik melakukan edukasi tentang pemeriksaan SADARI sekaligus melakukan pemeriksaan SADANIS pada remaja putri untuk meningkatkan program perawatan kesehatan dan membantu wanita muda untuk mendapatkan kebiasaan kesehatan yang baik.

\section{DAFTAR PUSTAKA}

1. Westmead Breast Cancer Institute. Fibroadenoma of the Breast Fact Sheet [Internet]. 2018 [dikutip 6 Januari 2019]. Tersedia pada: https://www.bci.org.au/breast-cancerinformation/fact-sheets/fibroadenoma-of-the-breast/

2. Angrainy R. Hubungan pengetahuan, Sikap tentang SADARI Dalam Mendeteksi Dini Kanker Payudara Pada Remaja. J Endur [Internet]. 2017;2(2):232-238. Tersedia pada: https://ejournal.kopertis10.or.id/index.php/endurance/article/download/1766/727

3. Kementerian Kesehatan R.I. Panduan Nasional Penanganan Kanker Payudara. Jakarta: Kementerian Kesehatan R.I.; 2015.

4. International Agency for Research on Cancer WHO. Latest Global Cancer data: Cancer Burden Rises to 18.1 million new cases and 9.6 million Cancer Deaths in 2018 [Internet]. 2018 Sep [dikutip 6 Februari 2019]. Tersedia pada: http://gco.iarc.fr/,

5. Kementerian Kesehatan R.I. Hari Kanker Sedunia. Jakarta: Kementerian Kesehatan R.I.; 2019.

6. Dinas Kesehatan Propinsi Sulawesi Tengah. Profil Kesehatan Provinsi Sulawesi Tengah 2014. Palu; 2015.

7. Dinas Kesehatan Propinsi Sulawesi Tengah. Profil Kesehatan Provinsi Sulawesi Tengah 2015. Palu; 2016.

8. Dinas Kesehatan Kota Palu. Profil Kesehatan Kota Palu 2014. Palu; 2015.

9. Dinas Kesehatan Kota Palu. Profil Kesehatan Kota Palu 2015. Palu; 2016.

10. Wantini NA, Indrayani N. Early Detection Of Breast Cancer With Clinical Breast Examination (CBE) On Women Of Childbearing Ageln Puskesmas Kalasan, Sleman, DIY. J Kebidanan Indones [Internet]. 1 Juli 2018 [dikutip 6 Juli 2020];9(2):14. Tersedia pada: https://stikesmus.ac.id/jurnal/index.php/JKebln/article/view/204 
11. Notoatmodjo S. Promosi Kesehatan dan Ilmu Perilaku Kesehatan. Jakarta: Rineka Cipta; 2012. 